\title{
Effect of Ginkgo biloba leaf extract on preservation of "Shatang" Orange
}

\section{Authors Info \\ W. Guoxia" ${ }^{1 *}$ C. Gang', L. Qing', Y. Yuzhen', L. Juan', Z. Zhihao', Z. Jin ${ }^{1}$ and W. Wenting ${ }^{1}$ \\ ${ }^{1}$ School of Life Sciences, Zhengzhou Normal University, Zhengzhou, Henan-450 044, China \\ ${ }^{2} S$ chool of Life Sciences, Zhengzhou University, Zhengzhou, Henan-450 000, China \\ *Corresponding Author Email : wgxia191919@sina.com}

\section{Edited by}

Prof. Muhammad Aqeel Ashraf

\section{Reviewed by}

Dr. K. Li

Dr. D. Li

\section{Abstract}

Aim: The objective of the study was to investigate the effect different concentrations of Ginkgo leaf extracts on the preservation of citrus.

Methodology: In order to study the effect of Ginkgo biloba leaf on preservation of orange, fresh "Shatang" orange were stored at $16^{\circ} \mathrm{C}$ after dipping in extract concentration of $25 \mathrm{gl}^{-1}, 12.5 \mathrm{~g} \mathrm{l}^{-1}$ and $6.25 \mathrm{~g} \mathrm{l}^{-1}$, with sterile water as control group. The weight loss, firmness, soluble solids contents, titratable acid contents, Vitamin C contents, flavonoid contents and total phenol contents of orange were measured every 2 days during storage period.

Results: The results showed that the extract of Ginkgo biloba leaves could reduce the weight loss and firmness, inhibit the decreases in the contents of soluble solids, titratable acid, Vitamin C, flavonoid and total phenol.

Interpretation: The main effective components of Ginkgo leaf extracts are Ginkgo flavonoid and lactone compounds, flavonoid is a kind of natural antioxidant which has broad-spectrum $\mathrm{c}$ and antimicrobial properties. A $6.25 \mathrm{~g} \mathrm{l}^{-1}$ leaf extracts of ginkgo biloba was the best concentration for the preservation of "Shatang" orange.

Key words: Antimicrobial activity, Flavonoid content, Ginkgo biloba, Preservation effect, Shatang orange

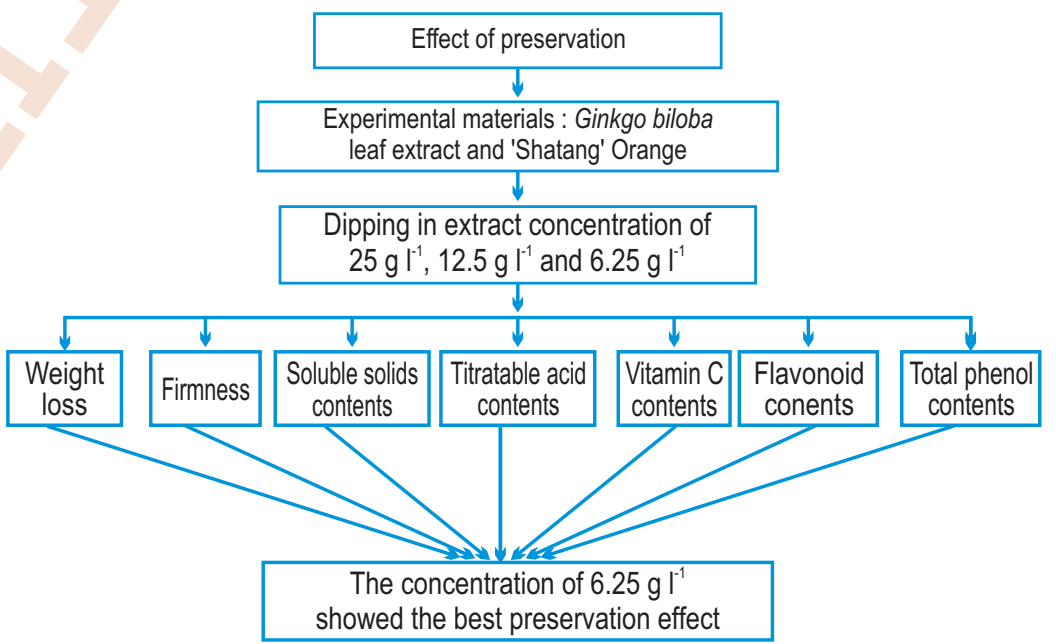

Citation: Guoxia, W., C. Gang, L. Qing, Y. Yuzhen, L. Juan, Z. Zhihao, Z. Jin and W. Wenting: Effect of Ginkgo biloba leaf extract on preservation of "Shatang" Orange. J. Environ. Biol., 40, 434-440 (2019). 


\section{Introduction}

Citrus reticulata Blanco is a plant which belongs to family Rutaceae. Citrus fruits are rich in nutrition and have excellent color, smell and taste. It can be eaten freshly and used for processing of juices, canned goods and other products. It also has certain medicinal value (Qu et al., 2013; Lijie and Feng, 2018), with a large cultivable area and high yield, China has become the largest producer of citrus fruits (Zhou et al., 2014), however, during post-harvest storage and transportation period, the fruits gets decayed and deteriorated due to poor environment mechanical damage, fungi and other microbial contamination and physiological diseases, which seriously affects its commodity properties and economic values, hindering the development of citrus industry (Xiong et al., 2015; Zahan et al., 2018). The chemical, physical and biological methods are mainly adopted to prolong the freshness of citrus fruit (Wu et al. 2014; Bakkali et al. 2014; Regnier et al., 2014; Ren et al. 2012; Liu et al., 2014). However, due to health consciousness, the use of safe, natura and environment-friendly plant extracts as the fresh-keeping agent has become the main research direction of storage and preservation of citrus (Hu et al., 2010; Zeng and Zhao, 2014; Ouyang et al., 2015; Xiong, 2014).

Ginkgo biloba is a deciduous tree. It is a multi-purpose economic tree species with an aggregative function of fruit, foliage, timber and ornamental (Cao, 2002). The main effective components of Ginkgo leaf extracts are flavonoid and lactone compounds (Chen et al., 2008; Nazihah et al., 2018). Flavonoid is a kind of natural antioxidant which has broad-spectrum antibacterial and antimicrobial properties (Huo et al., 2012; Nordin et al., 2018; Khan, 2018), so as a new kind of natural preservative, Ginkgo leaf extracts has great potential. In the past, the study of Ginkgo biloba leaf mainly focused on the research on the value of medicinal care, however studies on fruit preservation is meagre (Feng et al., 2013; Zhang et al., 2014). In this study, the effect of different concentrations Ginkgo biloba leaf extracts on the preservation of citrus was investigated, which provided a new idea and potential application value.

\section{Materials and Methods}

The leaves of Ginkgo biloba were collected from the campus of Zhengzhou Normal University, Zhengzhou, Henan. "Shatang" oranges were purchased from the local market. Ripe fruits with consistent maturity, similar size and free off diseases, insect pests or mechanical damage were chosen for standby application.

Extraction methods: The leaf extracts of Ginkgo biloba was prepared following the method of Wang (2006) with slightly modification. The extract was diluted $25 \mathrm{gl}^{-1} 012.5 \mathrm{gl}^{-1}$ and $6.25 \mathrm{gl}^{-1}$ respectively. Sterile distilled water served as control. "Shatang" oranges were cleaned and dried to place on Ginkgo biloba leaf extracts with different concentrations, and sterile distilled water for soaking $5 \mathrm{~min}$. Then, the "Shatang" oranges was wrapped with preservative film with a small hole was made on both sides. "Shatang" oranges were placed at $16{ }^{\circ} \mathrm{C}$ for storage. Measurements index such as weight loss rate of fruit, soluble solid content, Vitamin C content, firmness, titratable acid content, total phenol content and flavonoid content were determined on the $0^{\text {th }}, 2^{\text {nd }}, 4^{\text {th }}, 6^{\text {th }}, 8^{\text {th }}$ and $10^{\text {th }}$ day.

Biochemical parameters: The rate of fruit weight loss was determined by weighing method. Soluble solid content was determined by hand-held refractometer. Firmness of fruit was directly determined by the fruit firmness tester. Vitamin $\mathrm{C}$ was determined by 2, 6-dichlorophenol titration. The titratable acid content was determined by acid-alkali neutralization titrimetric method. Total phenol and flavonoid content was determined by hydrochloric acid - methanol colorimetric method.

Data analysis: The experiments were carried out in triplicate and the mean value was calculated for the results. Statistical analysis was performed using Excel 2007 and DPS11.5.

\section{Results and Discussion}

The rate of fruit weight loss represents the change in weight of citrus before and after storage and is the most significant indicator to determine the weight of citrus (He et al., 2006; Ying et al., 2018). The increase in weight loss rate reveals that the water content of the orange decreased, which prevents the normal metabolic action. The experimental results showed that the rate fruit weight loss of "Shatang" orange at different treatments increased with increase intime (Fig. 1). The difference in the fruit weight loss rate of "Shatang" orange at different treatments on the first two days was minimum, while gradually the difference began to increase on the $4^{\text {th }}$ day. Relatively speaking, the weight loss rate of the control was always at the highest level of the four treatments, the weight loss rate of $6.25 \mathrm{gl}^{-1}$ was always at the lowest level, and that of $25 \mathrm{gl}^{-1}$ and $12.5 \mathrm{gl}^{-1}$ was somewhere in between. This suggests that the treatment of Ginkgo leaf extracts reduced the loss of citrus weight. The effect of $6.25 \mathrm{gl}^{-1}$ treatment was relatively good.

The soluble solid content can be used to detect the maturity and quality of citrus. The results showed that the soluble solid content of "Shatang" orange at different treatments gradually decreased with the increase in time (Fig. 2). In general, the decrease in the soluble solid content of the control was most obvious, remaining at the lowest level among four treatments, while the soluble solid content of $6.25 \mathrm{gl}^{-1}$ treatment was always at a relatively high level. Except for $6^{\text {th }}$ day, when the $25 \mathrm{~g} \mathrm{I}^{-1}$ treatment was lower than that of the $12.5 \mathrm{~g} \mathrm{I}^{-1}$ treatment, it was seen that the treatment of ginkgo leaf extracts was beneficial to the retention of citrus soluble solid, and the effect of $6.25 \mathrm{~g} \mathrm{I}^{-1}$ treatment was relatively good. 


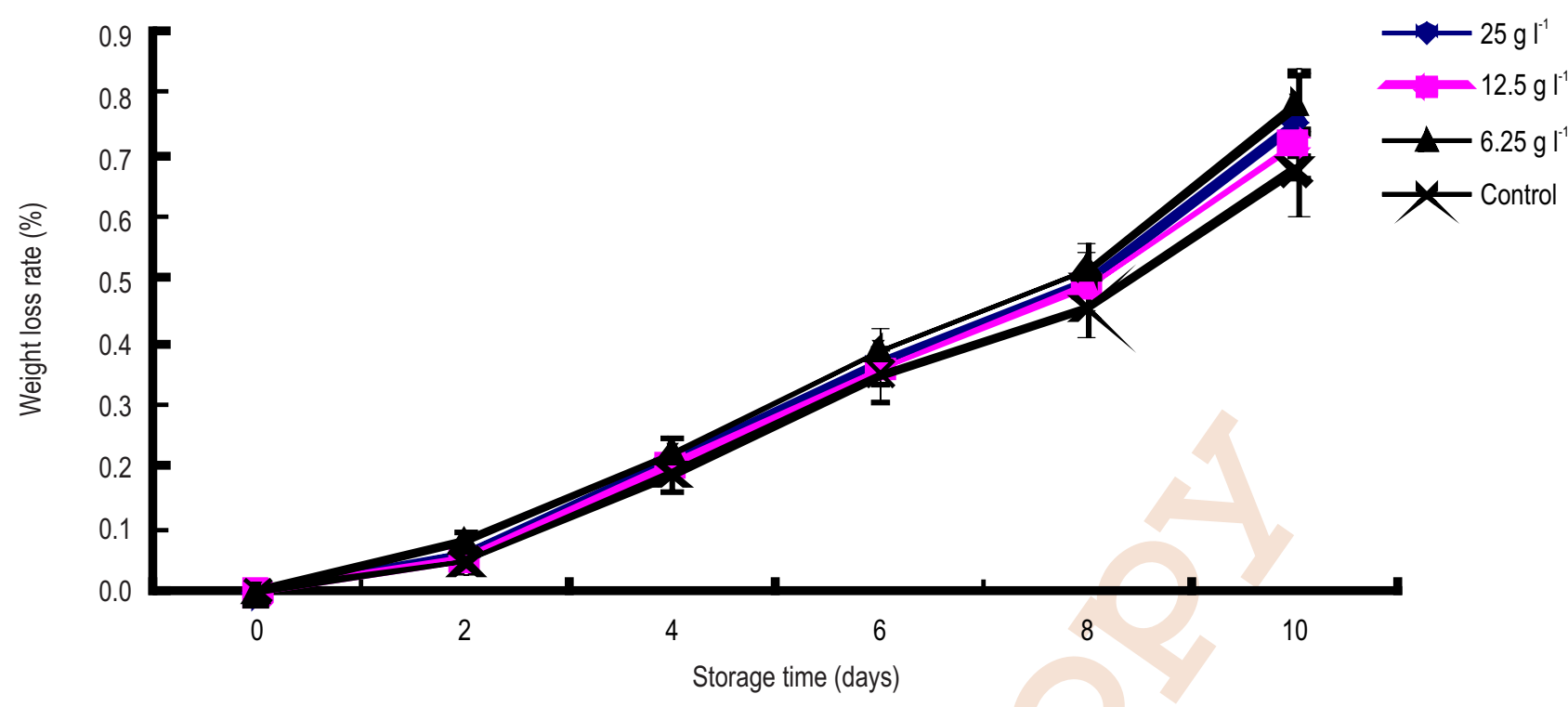

Fig. 1: Effect of different treatments on weight loss of "Shatang" orange.

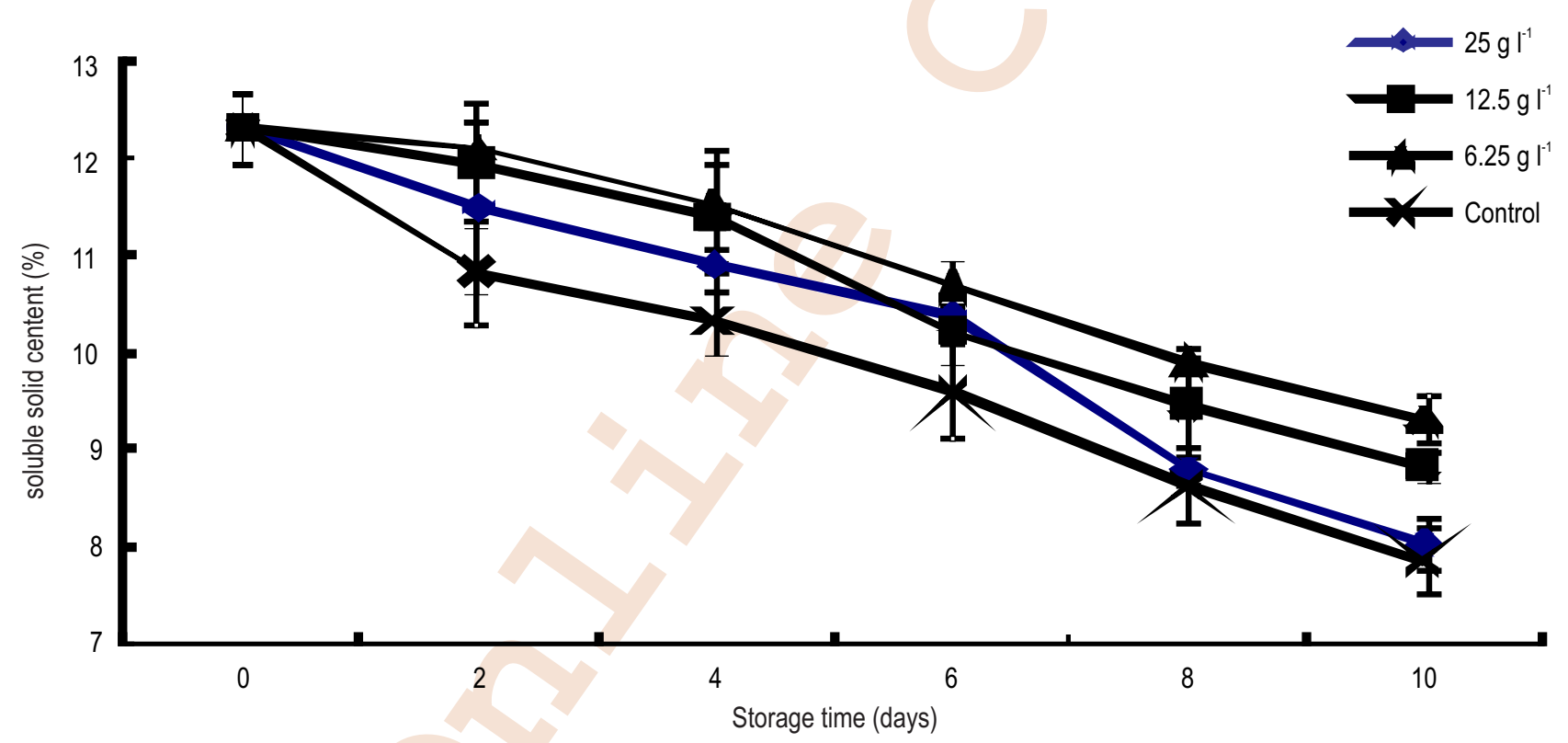

Fig. 2: Effect of different treatments on soluble solid content of "Shatang" orange.

Firmness is the most intuitive indicator to determine the citrus quality. Peel is the protective film of citrus, and decrease in the peel firmness indicates the decline of the citrus quality. The experimental results showed that the firmness of "Shatang" orange gradually declined with the increase in time (Fig. 3). It could be seen from the figure that the difference in firmness change of "Shatang" orange in two day treatment was minimum, while the difference gradually began to increase on the $2^{\text {nd }}$ day, the degree of firmness decrease was maximum from the $8^{\text {th }}$ day to $10^{\text {th }}$ day, on $10^{\text {th }}$ day, except the $6.25 \mathrm{~g} \mathrm{l}^{-1}$ treatment, the firmness values of "Shatang" orange of other three treatments were similar.
In the 6.25Y treatment, the firmness of "Shatang" orange always maintained the highest level, while that of "Shatang" orange in the control treatment was always the lowest level, and that of "Shatang" orange of $12.5 \mathrm{~g} \mathrm{l}^{-1}$ treatment and $25 \mathrm{~g} \mathrm{l}^{-1}$ treatment was located in between the two, and that of $12.5 \mathrm{~g} \mathrm{l}^{-1}$ treatment was always higher than that of $25 \mathrm{~g} \mathrm{l}^{-1}$ treatment. The results showed that the treatment of Ginkgo leaf extracts delayed the decrease in firmness.

Vitamin $C$ is one of the main in citrus. It is also a kind of reducing agent, but easily lost during storage process because of 


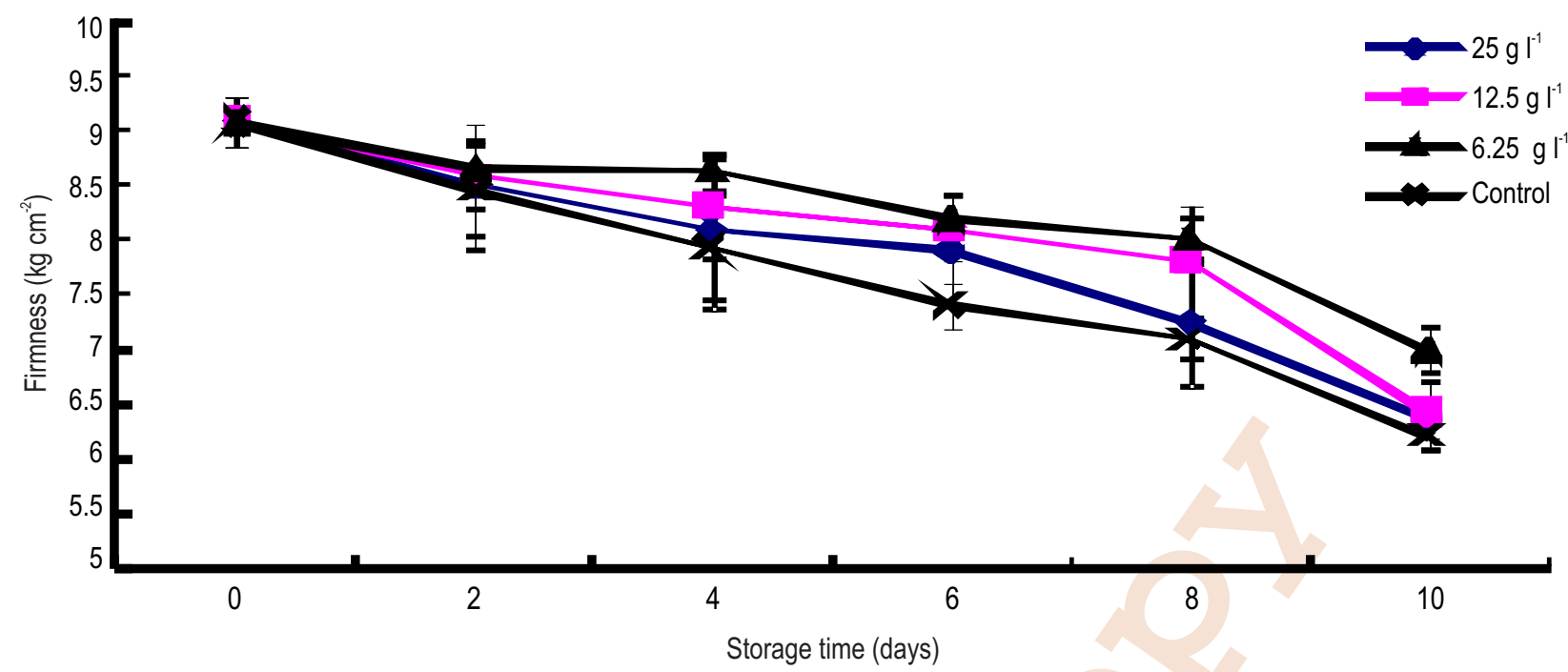

Fig. 3 : Effect of different treatments on firmness of "Shatang" orange.

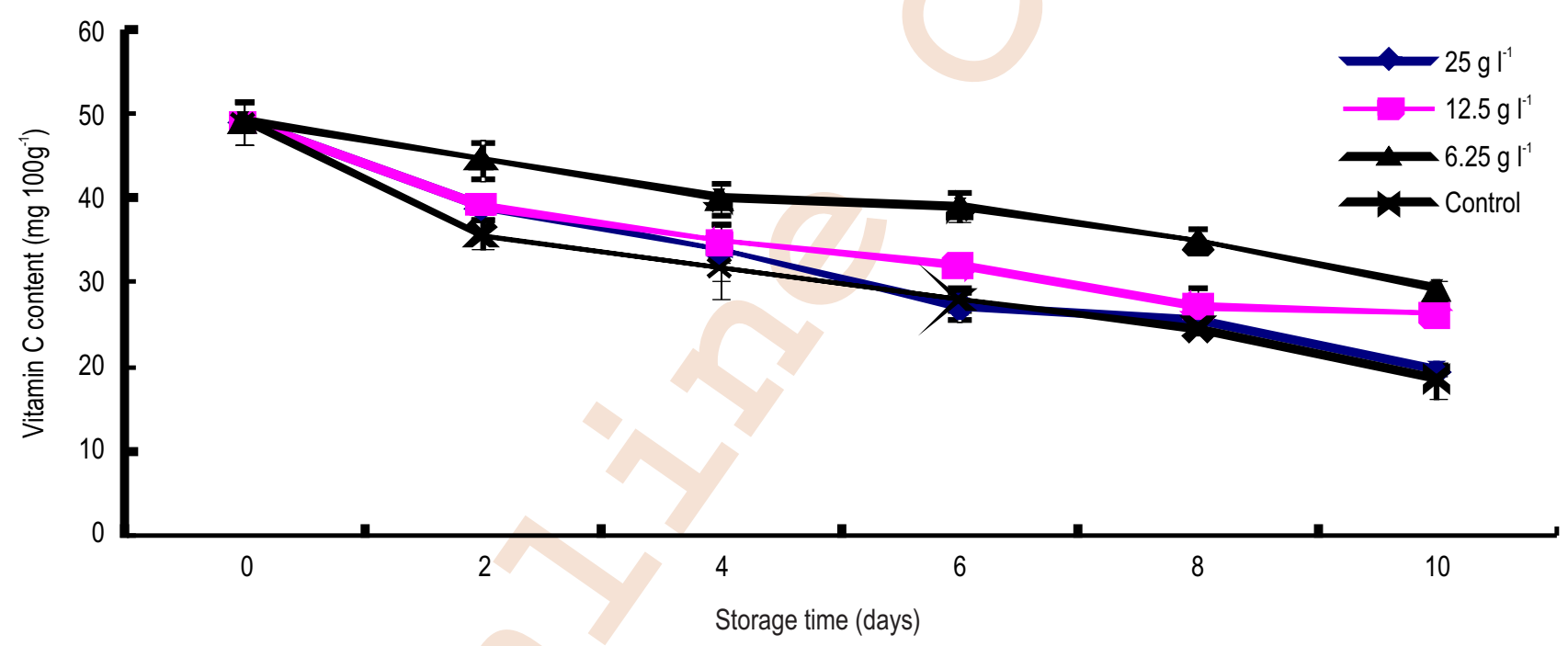

Fig. 4: Effect of different treatments on Vitamin C content of "Shatang" orange.

oxidation, therefore Vitamin $\mathrm{C}$ content is one of the important indexes for detecting the citrus quality. The experimental results showed that the Vitamin $\mathrm{C}$ content of "Shatang" orange gradually decreased with the extension of storage time (Fig. 4). The Vitamin C content of "Shatang" orange at the beginning of the treatment was $49.19 \mathrm{mg} 100 \mathrm{~g}^{-1}$, and that of "Shatang" orange of control was

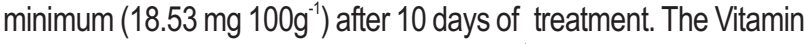
$\mathrm{C}$ content of "Shatang" orange at $6.25 \mathrm{~g} \mathrm{l}^{-1}$ treatment was always highest, while that control treatment was lowest. Except on $6^{\text {th }}$ day, the Vitamin $\mathrm{C}$ content in $12.5 \mathrm{~g} \mathrm{I}^{-1}$ treatment was higher than that of "Shatang" orange in at $25 \mathrm{~g} \mathrm{l}^{-1}$ treatment. The results showed that the Ginkgo leaf extracts were beneficial for retaining Vitamin $\mathrm{C}$ content in citrus, and the effect of $6.25 \mathrm{~g} \mathrm{I}^{-1}$ treatment was relatively good.
Titratable acidity is one of the main indicator of fruit quality and, like sugar, it is an important factor that affects the flavor quality of fruit (Li et al., 2008). The results showed that the titratable acid content of 'Shatang' orange gradually decreased with the increase in storage time (Fig. 5). The titratable acid content in $6.25 \mathrm{~g} \mathrm{l}^{-1}$ and $12.5 \mathrm{~g} \mathrm{I}^{-1}$ treatments was relatively high and similar, while the content in $25 \mathrm{~g} \mathrm{l}^{-1}$ treatment and control treatment was relatively low. The rate of decline in the next 4 days after treatment decreased significantly. The difference in the titratable acid content of 'Shatang' orange in three different Ginkgo leaf treatments were not obvious, and the control treatment was lower than other three treatments from $2^{\text {nd }}$ day. The results showed that the leaf extracts were beneficial to retain the 


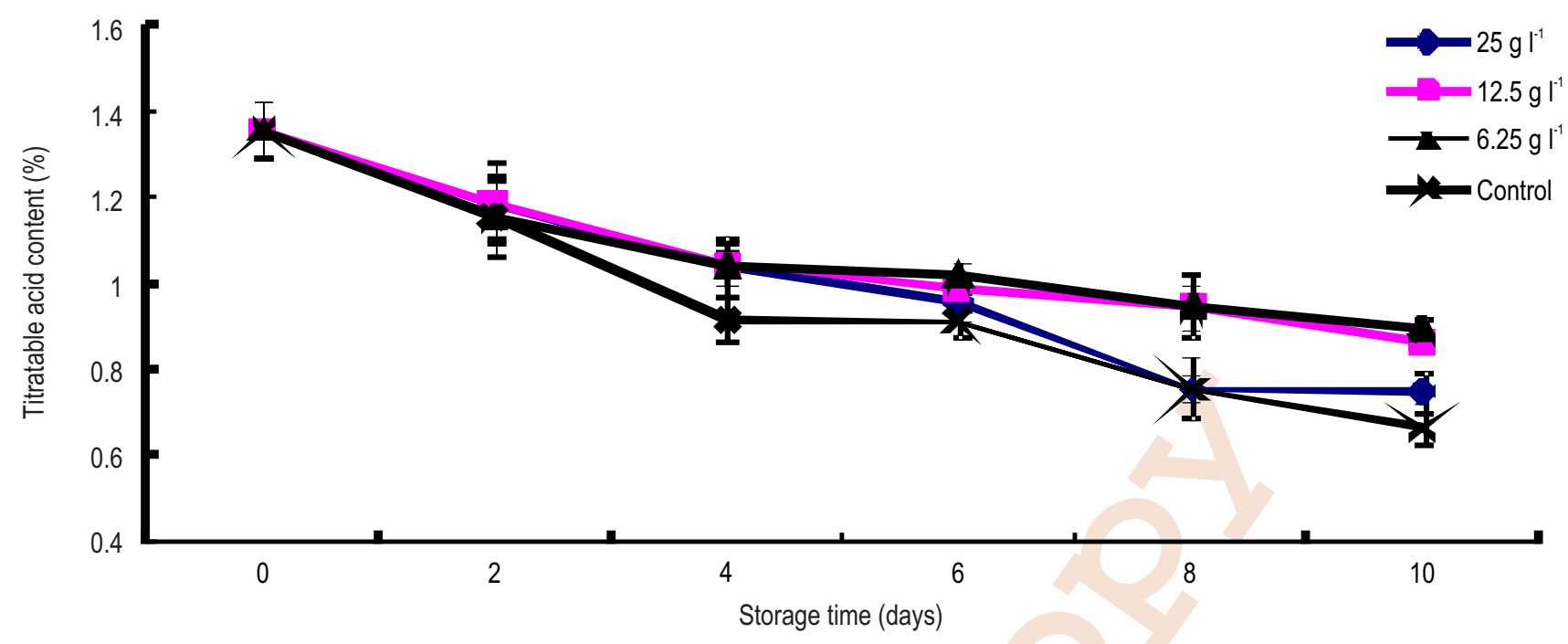

Fig. 5: Effect of different treatments on titratable acid content of "Shatang" orange.

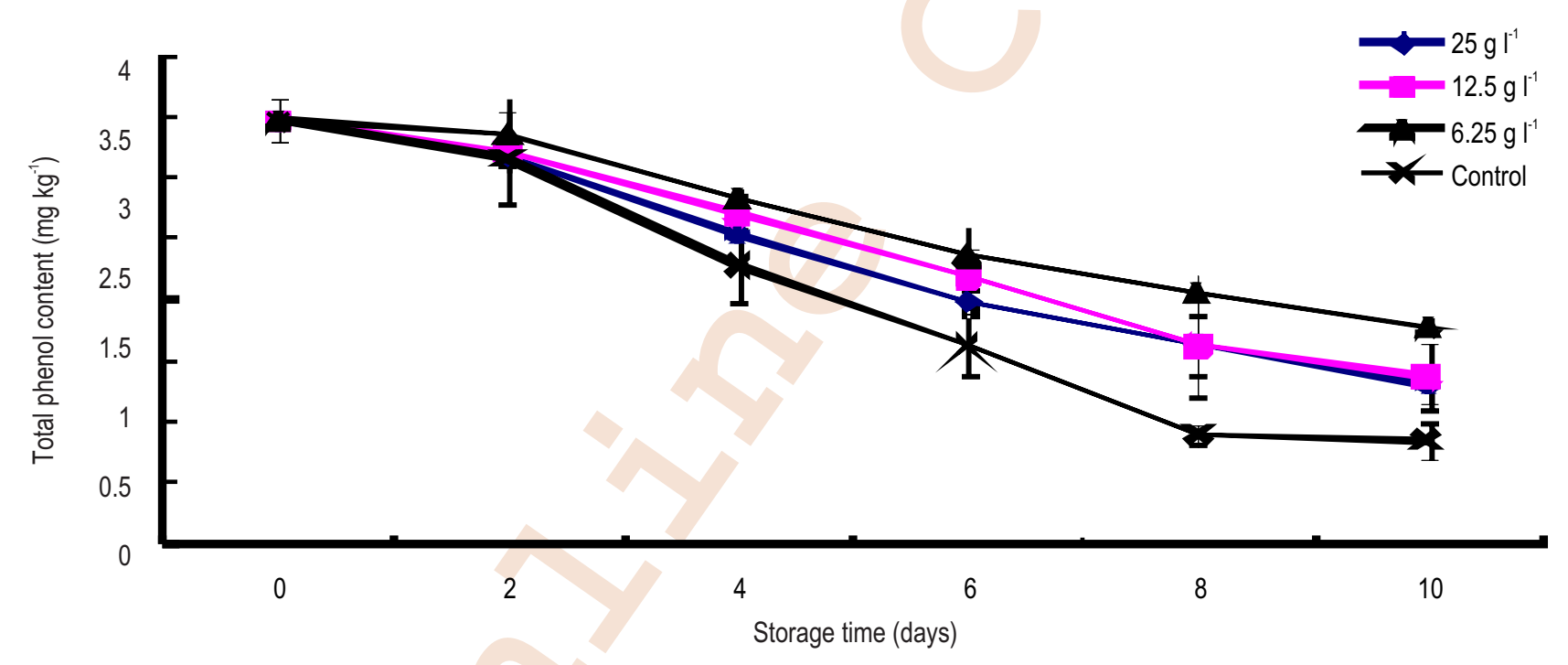

Fig. 6: Effect of different treatments on total phenol content of "Shatang" orange.

titratable acid content of citrus, and the effects of $6.25 \mathrm{~g} \mathrm{l}^{-1}$ and $12.5 \mathrm{gl}^{-1}$ treatments were relatively good.

Total phenol is the general name of all phenolic substances, and the phenolic substance plays an antioxidant role in fruits and vegetables, which can be used as one of the indicators for determining the fruit quality. As a whole, the total phenol content of "Shatang" orange decreased with the increase of time (Fig. 6). Fig. 6 shows that two days before, except for 6.25 $\mathrm{gl}^{-1}$ treatment, the total phenol content of "Shatang" orange in the other three treatments was similar and that of "Shatang" orange in the treatments from $2^{\text {nd }}$ day to $8^{\text {th }}$ day dropped quickly. For the last two days, except for $6.25 \mathrm{gl}^{-1}$ treatment, the total phenol content of "Shatang" orange in the other three treatments basically remained unchanged. The total phenol content of $25 \mathrm{~g} \mathrm{l}^{-1}$ treatment was similar to that of the $12.5 \mathrm{~g} \mathrm{I}^{-1}$ treatment, indicating that the effect of two concentrations on total phenol of "Shatang" orange were similar. The total phenol content was highest in 6.25 $\mathrm{g} \mathrm{I}^{-1}$ treatment, and lowest in the control treatment. The results showed that the leaf extracts had a delayed effect on the decrease of total phenol content in citrus.

Flavonoid, also known as vitamin $\mathrm{P}$, are secondary metabolite of plant. Flavonol is the main substance that determines the color of citrus can directly reflect the changes in citrus quality. Experimental results showed that the flavonoid content in "Shatang" orange gradually decreased with the increase in time (Fig. 7). The flavonoid content of "Shatang" 


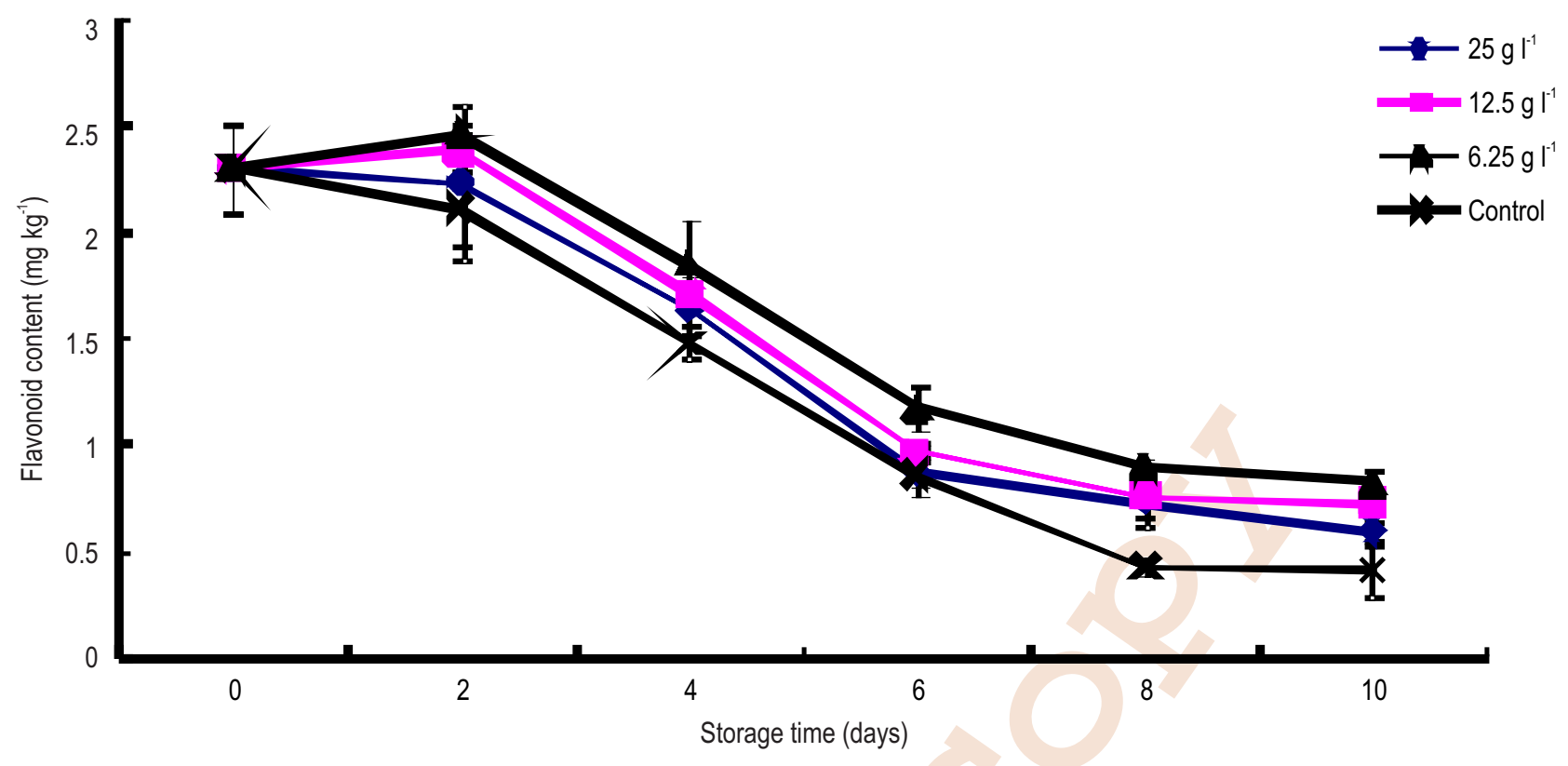

Fig. 7: Effect of different treatments on flavonoid content of "Shatang" orange.

orange in $6.25 \mathrm{~g} \mathrm{l}^{-1}$ treatment and $12.5 \mathrm{~g} \mathrm{l}^{-1}$ treatment slightly increased in the first two days, while that of "Shatang" orange in the treatments from $2^{\text {nd }}$ day to $8^{\text {th }}$ day fell faster, and the declining quantity of flavonoid content of "Shatang" orange in the control treatment was highest, "Shatang" orange in the control treatment changed little in the last two days. The flavonoid content of "Shatang" orange in $6.25 \mathrm{~g} \mathrm{l}^{-1}$ treatment was always highest while that of control treatment was always lowest. The results showed that the treatment of Ginkgo leaf extracts was beneficial to the retention of flavonoid content of citrus.

Citrus is a typical non-respiration climacteric fruit and is easy to lost weight in the process of post-harvest storage. Respiration consumption can also lead to unceasing decrease of sugar and acid contents, especially more significant decrease of the acid content, which lowers the freshness and commodity value (Wang, 2009). Therefore, the storage preservation process is very important to the weight and quality of citrus, directly affecting the economic benefits of fruit farmers. In recent years, natural fruit and vegetable fresh-keeping agent has become a major research direction (Guo et al., 2009; Ren et al., 2010; Regnier et al., 2014). The main effective components of Ginkgo leaf extracts are Ginkgo flavonoid and Ginkgo terpene lactone compounds, and the nutrients such as polysaccharide, phenols, organic acids and multi-amino acids, vitamins and trace elements are also included. Previous studies have mainly focused on the research and development of its medicinal effects (Chen et al., 2008).

As for the fruit and vegetable fresh-keeping, there was only related research on the apple preservation. Feng Jinxia et al.
(2013) treated fresh-cut apples with Ginkgo leaf extracts of three different concentrations, and found that it could to a certain extent; reduce the activity of polyphenol oxidase in the fresh-cut apples, inhibiting browning, reducing moisture loss, maintaining the firmness of apple slices, improving the sensory quality of freshcut apples and delaying the reducing rate of Vitamin C content, which could better keep the quality of fresh-cut "Red Fuji" apple. Zhang Meifang et al. (2014) compared the preservative effects of Ginkgo leaf extracts and sodium alginate composite film on the fresh-cut apples, and found that these two treatment methods could well maintain the sensory quality of fresh-cut apples, but the preservative effects of Ginkgo leaf extracts combined with sodium alginate film was the best. In this study, fresh "Shatang" oranges treated with Ginkgo leaf extracts of the concentrations of $25 \mathrm{~g} \mathrm{I}^{-1}$, $12.5 \mathrm{gl}^{-1}$ and $6.25 \mathrm{gl}^{-1}$, and found that compared with the control, the treatment of Ginkgo leaf extracts could, to a certain extent, reduce moisture loss, maintain the firmness of "Shatang" orange, delay the decrease of soluble solids, total phenol, titratable acid, flavonoid and Vitamin $\mathrm{C}$ content, which had more ideal preservation effects. The $6.25 \mathrm{gl}^{-1}$ leaf extracts was found best for preserving "Shatang" orange. The results showed that Ginkgo leaf extracts had great value in the development of natural preservatives of citrus.

\section{Acknowledgments}

This research was Supported by Henan Foundation and Frontier Technology Research Project (162300410161), the Science and Research Creative team of Zhengzhou Normal University, and Innovative Experimental Program for Undergraduates of Zhengzhou Normal University (DCZ2016008). 


\section{References}

Bakkali, F., S. Averbeck and D. Averbeck: Biological effects of essentia oils: A review Food Chem. Toxicol., 46, 446-475 (2008).

Cao, F.l.: Chinese Ginkgo[M]. Nanjing: Phoenix Science Press (2002).

Chen, X.J., C.Z. Wang and J.Z. Ye: Research progress of chemica constituents of Ginkgo biloba Linn. leaves and their application. Biomass Chem. Engine., 42, 57-62 (2008).

Feng, J.X., L. He and X.M. Pu: Effect of ethanol extract of Ginkgo biloba leaves on the quality of fresh-cut 'Red Fuji' Apples. Food Sci., 34, 263-267 (2013).

Guo, Y.F., Y. Liu and X.L. Li: Compound plant preservative and preservation effect for cherry tomatoes. Chin. J. Trop. Crops, $\mathbf{3 8}$, 365-373 (2017)

$\mathrm{He}$, L.Y., X.K. He and Y.F. Gao: Studies on the function of $\mathrm{KMnO}_{4}$ for the storage of fruit. Pack. Engg., 27, 51-52 (2006).

Hu, J.H., L.N. Ma and L. He: Antifungal activities of 47 plant extracts against three citrus post-harvest storage pathogens. South China Fruits, 39, 1-4 (2010).

Huo, Y.Q., J. Yin and X. Chen: Studies on ultrasonic-assisted extraction and anti-microbial activities of flavonoids from Ginkgo leaves. The Food Indu. 33, 47-49 (2012).

Khan, M.M.H.: Occurrence, distribution, host preference and damage severity of Red pumpkin beetle -A review. Malays. J. Halal Res., 1 03-09 (2018).

Li, F.M., Q.X. Zhou and W.X. Li: Effect of clove extract and chitosan compound on strawberry fresh-keeping. J. Qing. Agric. Univ. Nat. Sci., 25, 298-300 (2008).

Lijie, L. and Y. Feng: Astudy on the rhythm and respiratory characteristics of zhuang language. Acta Sci. Malays., 2, $26-28$ (2018).

Liu, H.Q., H.J. Li and K.H. Xiang: Anti-pathogen activities and effect of four food preservatives on postharvest quality of citrus. Food Sci. $35,210-214$ (2014)

Nazihah, I., M.S. Zaini, R. Shahari, C.N.A. Che Amri and N.M. Tajuddin Diversity and distribution of fern species in selected trail in Kuantan Pahang. Sci. Herit. J., 2, 04-09 (2018).

Nordin, N.F.H., N.H.S. Ibrahim and A.J.K. Chowdhury: Physico-chemical parameters and bacterial composition in Sungau Pusu Gombak. Sci. Herit. J., 2, 10-12 (2018).

Ouyang, X.Y., Z.Q. Wu and D.J. Wan: Film forming of zein and its application in citrus preservation. J. Hub. Univ. Technol., 30, 20-23 (2015).

Qu, L.W., Y.T. Tan and Y.H. Zhou: Research progress innatural coating materials of citrus fruit storage. Sci. Technol. Food Ind., 34, 379-
$382(2013)$.

Regnier, T., S. Combrinc and W. Veldman: Application of essential oils as multi-target fungicides for the control of Geotrichum citriaurantii and other postharvest pathogens of citrus. Industrial Crops and Products, 61, 151-159 (2014)

Ren, Y.F., C. Liu and J.Y. He: Effect of coptis chinensis franch-chitosan film on preservation of valencia orange fruits. Food Sci., 33, 291297 (2012).

Ren, Y.F., C. Liu and L.L. Xu: Studies on inhibitory effects of herbal extracts against postharvest pathogen from citrus fruits. Northern Horticulture, 23, 179-181 (2010).

Wang, G.X., F.L. Cao and J. Chen: Progress in researches on the pharmaceutical mechanism and clinical application of Ginkgo biloba extract on various kinds of diseases. Chin. J. Integ. Medi., 12, 234-239 (2006)

Wang, H.C.: Effect of carboxymethyl chitosan coating on quality of oranges. Hub. Agric. Sci., 48, 946-948 (2009).

Wu, W., E. Zhu and Z.X. Chen: The application of sodium carbonate in the antisepsis and preservation of postharvest early mature citrus unshiu Marc. Storage and Process., 14, 9-12 (2014).

Xiong, Y.B., X.J. Yan and J. Yan: Development and utilization of new preservatives for citrus storage. Food Science, 36, 284-289 (2015).

Xiong, Y.H.: Effects of gardenia jasminoides ellis preparation on storage and fresh-keeping of Citrus siensis osbeck fruits. Northern Horticulture, 22, 157-159 (2010).

Ying, H.S., M.S. Anuar and M.Z.M. Nor: Drying, colour and sensory characteristics of 'Berangan' Banana (Musa accuminata) flesh dried using a microwave oven. Malays. J. Halal Res., 1, 10-14 (2018).

Zahan, T., A. Hashem, M. Rahman, R.W. Bell and M. Begum: Efficacy of herbicides in non-puddled transplanted rice under conservation agriculture systems and their effect on establishment of the succeeding crops. Acta Sci. Malays., 2, 17-25 (2018).

Zeng, X.Y. and L.Z. Zhao: Effect of citrus peel essential oil on the preservation of chilled pork 'Xuefeng'Honey orange. J. Nuc. Agric. Sci., 28, 2208-2214 (2014).

Zhang, M.F., L. He and J.X. Feng: Effects of composite coating consisting of Ginkgo biloba leaf extract and sodium alginate on quality of fresh-cut 'Red Fuji'Apples. Food Science, 35, 263-267 (2014)

Zhou, M.J., C.P. Wan and J.Y. Chen: Research progress on inhibition of citrus postharvest diseases and preservation effects of plant extraction. Northern Horticulture, 2, 186-190 (2014). 